\title{
O último trem para Alexandria
}

\section{LUIZ BEVILACQUA ${ }^{I}$}

\section{O Brasil na nova onda de choque}

$\mathrm{N}$

O INício do século XIX, a revolução industrial já estava instalada. Consolidou-se no decorrer daquele século e entrou com toda força no século XX. Iniciada no Reino Unido, provocou prontas reações competitivas em alguns países europeus e talvez com pouco atraso também nos Estados Unidos. Essa inferioridade com relação à Europa incomodava. Charles Elliot, então reitor de Harvard, declarava no início do século XX (James, 1930):

Concentrei aqui especial atenção às escolas dedicadas à educação de jovens para as artes e ofícios que requerem algum conhecimento de princípios científicos e suas aplicações, às escolas que formam mestres, superintendentes e projetistas para as numerosas indústrias francesas. que exigem gosto, habilidade e instrução técnica especial. Nós precisamos dessas escolas aqui, no nosso país. Eu não posso deixar de pensar que um conhecimento profundo do que a França achou útil para o seu desenvolvimento, possa algum dia me permitir também ser útil ao meu país. Neste momento, é humilhante ler os números que exibem as crescentes importações de todos os tipos de produtos manufaturados para a América. Especialmente será do interesse de Massachusetts fomentar por todos os meios em seu alcance a manufatura dos produtos que são sua principal força.

Na realidade, Elliot liderou a reforma da educação nos Estados Unidos, que, para resumir, basta dizer que privilegiou no seu plano pedagógico o estímulo à criatividade, independência intelectual e o exercício da liberdade para que cada estudante pudesse escolher o seu próprio rumo. Com os requisitos de créditos em disciplinas reduzidos ao essencial, permitiu que os jovens estudantes tivessem desde cedo tempo para aprender e a oportunidade de escolher seus próprios caminhos. Assim, abriu caminho para que as novas gerações libertassem o país do domínio industrial que se formava. Antes do fim do século XX os Estados Unidos passaram a ser semelhantes à Alexandria dos tempos modernos. O lugar onde se privilegiava o avanço do conhecimento e as invenções tecnológicas. $\mathrm{O}$ atrativo universal dos apaixonados pelo saber e fazer criativo.

O Brasil escolheu o caminho oposto. Não deu importância à educação, deixando milhões de crianças sem oportunidade de estudar. E mesmo para alguns privilegiados, em lugar de apostar na inteligência e criatividade, preferiu enjaular os estudantes em grades curriculares, desencorajar a criação de universidades em favor da independência de escolas profissionalizantes, escolas de engenharia, medicina e direito, submetendo-se docilmente à dominação industrial. Contribuem para esse quadro as travas burocráticas e o complexo de inferiorida- 
de que nos afetam até hoje. Dois registros exemplares relativos a duas das nossas mais prestigiosas universidades confirmam essa afirmação.

O primeiro refere-se à criação de Universidade do Rio de Janeiro, criada "por decreto" em 1920. Diz o relatório de seu primeiro reitor, Benjamin Franklin Ramiz Galvão, encaminhado ao ministro de Estado e Negócios da Justiça, Joaquim Ferreira Chaves, em 1921 (Favero, 2000):

Cumpre-me oferecer à atenção do governo o relatório do que de mais importante ocorreu na Universidade do Rio de Janeiro, durante o ano de 1921, que acaba de findar. Ele será, forçosamente, sucinto, já porque a Universidade, criada pelo decreto n.14.343, de 7 de setembro de 1920, e regulada pelo regimento constante do decreto n.14.572, de 23 de dezembro do mesmo ano, está, apenas, em início de funções, já porque as condições em que ela se instituiu forçaram a mesma Universidade a permanecer dentro dos moldes estabelecidos pelo decreto n.11.530, de 18 de março de 1915, que é, por enquanto, lei vigente. Não errarei afirmando, pois, que a Universidade do Rio de Janeiro está, apenas, criada in nomine, e por esta circunstância, se acha, ainda, longe de satisfazer o desideratum do seu Regimento: estimular a cultura das ciências, estreitar, entre os professores, os laços de solidariedade intelectual e moral, e aperfeiçoar os métodos de ensino.

A Universidade de São Paulo começou com um propósito também consistente, mas com o traço lamentável da falta de confiança em nós mesmos e o reconhecimento da submissão à França, enquanto nos Estados Unidos o propósito de Elliot era competir com a França. Segundo Crodowaldo Pavan (Faculdade..., 1993):

A FFCL foi planejada para ser o centro da Universidade de São Paulo e teve sucesso porque para ela foram convidados diversos professores e pesquisadores estrangeiros, assim como brasileiros de alto nível. Se ela tivesse começado somente com docentes brasileiros o fracasso teria sido total. Note-se que à época o Brasil se curvava diante da influência cultural da França. Somando todos esses fatores e a necessidade de formar-se profissionais para áreas do conhecimento em que o atraso brasileiro era incontestável, estruturou-se a Faculdade de Filosofia, cujas finalidades principais eram: preparar trabalhadores intelectuais para o exercício de altas atividades culturais, de ordem desinteressada ou técnica; preparar docentes para o magistério do ensino básico e superior; realizar pesquisas nos domínios da cultura que eram o objeto de uma Faculdade de Filosofia, Ciências e Letras.

Em ambos os casos a Universidade como tal não se consolidou. As escolas de engenharia, medicina e direito não permitiram. A ciência, que foi o fundamento da revolução industrial, era abandonada em favor das cópias tecnológicas e do comércio. Desvalorizada a capacidade de competir em inteligência e criatividade, a nossa sociedade entocou-se em comércio valorizando a habilidade de produzir riqueza sem produzir valor, fazendo chegar à atual conjuntura onde os bancos estão no ápice das instituições mais ricas e mais prestigiosas no Bra- 
sil. Como a burocracia é um instrumento de grande utilidade para se ganhar dinheiro sem produzir, tudo converge para o poço da ignorância montada em dinheiro.

Bem, tudo isso para mostrar a nossa irrecuperável inserção no mundo de nações tecnologicamente independentes. Para que não se diga que são projeções internas pessimistas, destaco a visão do mundo desenvolvido sobre novo futuro. É assim que somos vistos (Alper, 2016):

Ao mesmo tempo aqueles países falam mais sobre a captura de valores nacionais, de suas políticas de inovação enfatizando a necessidade de seus centros estarem conectados globalmente a outros centros. Há um debate interessante em andamento, disse O'Sullivan, sobre o fluxo de conhecimento em um momento em que nações com economias de inovação consolidadas estão fazendo parcerias com países cujas economias de inovação são menos consolidadas. Essa divisão do trabalho tende a promover a pesquisa científica e tecnológica em países mais maduros, enquanto a prototipagem, aumento de escala e fabricação ficam no que ele chamou de "catch-up" economies. (economias em busca de desenvolvimento).

Então não estamos falando de conjecturas pessimistas. São fatos reais. Mas se até recentemente poderia haver uma tênue esperança, os últimos três anos selaram o nosso destino de submissão no mundo industrial. Até recentemente, a nossa evolução industrial foi submetida a uma sequência de flutuações. Contam-se, entre muitas outras, Fábrica Nacional de Motores, Celma, Vale do Rio Doce, Agroceres, Gurgel, Embraco, Metal Leve, que após um breve período de crescimento foram descontinuadas ou transferidas para controle externo. Isso aconteceu não por incompetência, mas por falta de apoio do Estado; na realidade, pode-se dizer pelo exercício do poder de destruição do Estado (Mazzucato, 2014).

Particularmente crítica foi a última década do século passado. Seguiu-se a esse período uma flutuação positiva por um período de dez anos, neutralizada recentemente com a catástrofe que vem de selar nosso destino por muitos anos futuros. Foi a flutuação derradeira no processo de criação e destruição das nossas modestas iniciativas de reação industrial. O projeto de destruição, seja pela transferência do controle para empresas estrangeiras, seja pela proibição de entrar em concorrências, foi bem-sucedido. Estão sendo desmontadas: Petrobras, Embraer, JBS, e as cinco grandes empresas de construção civil (Odebrecht, Camargo Corrêa, Andrade Gutierrez, OAS Engenharia e Queiroz Galvão).

Sobrepondo-se a essa verdadeira catástrofe está às nossas portas uma nova revolução, "a revolução cultural” (Altbach; Reisberg, 2017; Alemanha, 2017). Uma onda gigantesca que vai invadir o mundo e inibir o desenvolvimento do pensar independente de modo semelhante à revolução industrial que inibiu o desenvolvimento do agir autônomo. Estarão sujeitos à dominação cultural os países fracos onde a educação não tem inserção social forte e nem está nas prioridades reais do Estado, mas sempre está declaradamente nas suas prioridades 
virtuais. São vários os indicadores. Cito um recente, publicado no El Pais em janeiro deste ano. Diz a notícia.

A União Europeia lança um ambicioso plano para que em 2025 haja 20 campi transnacionais. A ideia surgiu numa cúpula em Gotemburgo (Suécia) em novembro de 2017, coincidindo com os 30 anos do programa Erasmus, mas é agora que começa a contagem regressiva. As universidades estão se mobilizando nas últimas semanas para criar consórcios de campi em pelo menos três países diferentes, compartilhando alunos - que se quiserem poderão começar sua formação num país e terminá-la em outro -, pesquisas e professores. Em 28 de fevereiro termina o prazo para que as alianças se apresentem ao programa-piloto, dotado de um orçamento de 30 milhões de euros (128,2 milhões de reais). Seis consórcios serão escolhidos para colocar o plano em funcionamento no final deste ano. Os grupos rejeitados terão outra oportunidade em 2020.

Recordemos por um instante que a revolução industrial eliminou os artesãos do sistema de produção. Os processos produtivos foram revistos e transferidos para as fábricas que com os recém-inventados equipamentos e métodos de acionamento passaram a dominar o mercado substituindo a mão de obra artesanal. A produção saiu do campo e transferiu-se para os conglomerados fabris. Direta ou indiretamente, o conhecimento científico contribuiu para a revolução industrial. O substrato científico incorporado na cultura britânica no final do século XVIII e início de XIX permeou para alimentar as iniciativas tecnológicas. Ao lado desse motor, podemos dizer quase invisível, outros fatores, como o retorno financeiro das novas descobertas, a possibilidade de exclusividade de produção com o registro de patentes e a consequente dominação do mercado mundial, foram atrativos determinantes para impulsionar a revolução industrial. Aparentemente os problemas sociais causados pela nova cadeia de produção não foram considerados e acabaram por originar graves consequências que se espalharam por todo o mundo (Gregory, 2008).

Atualmente, os papeis se invertem. A tecnologia é o substrato sobre o qual está sendo montada a revolução cultural. A facilidade de transferir informação permite que se criem canais de conhecimento que podem alimentar o mundo inteiro de uma única sede. Portanto, as fábricas que transferiram para seu espaço a produção espalhada pelo campo estão servindo de protótipo para as universidades transnacionais. Os professores, espalhados pelas universidades e institutos, são os artesãos contemporâneos com morte anunciada. $\mathrm{O}$ conhecimento gerado nos grandes centros transnacionais será climatizado e canalizado nas devidas proporções, via cursos on line, para os países culturalmente periféricos. Novas tecnologias, como holografia e impressão tridimensional, serão incorporadas nos cursos virtuais. As universidades nos países periféricos serão reduzidas a filiais de acompanhamento e propaganda. Além de polo de comunicação, terão também a função de encaminhar para as centrais as melhores cabeças que contribuirão lá para o alargamento dos horizontes do conhecimento e para a maior eficiência do processo de trans- 
ferência. Os problemas de linguagem serão superados ou com o auxílio dos que dominam o mesmo idioma lotados na sede, ou pela tradução verbal simultânea.

A redução drástica do número de universidades será compensada pela criação e expansão de centros de reprodução. A gestão dos cursos, suplementos locais, credenciamento e cumprimento de requisitos legais necessitarão desses centros de reprodução espalhados pelo país, as "Unidade de Reprodução e Acompanhamento de Conhecimento para o Ensino Superior" (Uraces - essa denominação é uma invenção minha). De fato, distribuição em rede pelo país favorece o maior número de clientes (designação preferencial da nossa época para indivíduos pagantes, qualquer que seja o serviço) e maior arrecadação, por suposto. Assim, embora o professor universitário seja uma opção em extinção, haverá uma grande abertura para posições técnico-administrativas, monitores, auxiliares, superintendentes, e esse tipo de função subalterna que será exercida com muito orgulho e com grande reconhecimento pela matriz. Com certeza um restrito número de posições será reservado para a prestigiosa função de CEO-Uraces.

A iniciativa europeia de organização de universidades transnacionais, já comentada acima, que é consistente e provavelmente será muito bem qualificada, foi precedida de outras iniciativas já em andamento, como a Fundação Universitária Iberoamericana (Funiber):

A FUNIBER é uma instituição acadêmica dedicada à ciência e à pesquisa que estabelece redes de cooperação de universidades e instituições profissionalizantes a fim de oferecer uma Educação Global respeitando, ao mesmo tempo, as identidades locais. As três premissas fundamentais da FUNIBER são:

- Promover a criação de programas interuniversitários

- Apoiar o desenvolvimento e atividades de Projetos de Cooperação Internacional.

- Soluções para educação sob encomenda e gestão do conhecimento para empresas e instituições.

E para uma perspectiva global, além do relato de iniciativas em andamento, são instrutivas as previsões feitas no artigo de Jason Lane e Kevin Kinser (2015), do qual destaco os seguintes trechos:

Com o declínio dos subsídios do governo nos seus próprios países, preocupações com o aumento das anuidades e aumento da competição para atrair estudantes, algumas escolas de ensino superior e universidades estão procurando novas maneiras de expandir sua base econômica, através da oferta de cursos no exterior, obtenção de verbas externas para pesquisa, e estabelecimento de relações com doadores em outros países $[\ldots]$

A presença física é útil e, às vezes, necessária. Além disso, às vezes é mais fácil expandir e ser inovador em um país diferente, onde as regras e regulamentos das nações anfitriãs (ou estados) não são particularmente inibidoras 
de ação. Nos EUA, descobrimos que, embora os padrões de credenciamento se apliquem às atividades internacionais, muitos regulamentos estaduais não se estendem além de suas fronteiras.

Do mesmo modo como se procederam as implantações das flutuações de desenvolvimento industrial, estaremos muito breve enfrentando as flutuações do sistema educacional. Diante desse quadro, que embora possa ser classificado de pessimista, deve ser considerado, precisamos procurar possíveis saídas. Sempre existem saídas. As universidades transnacionais estão às nossas portas, como tudo indica, e não temos a cultura necessária nem apoio de Estado suficientes para evitar a invasão, como tem demonstrado a nossa história, é inútil qualquer esboço de resistência. Assim resta-nos tornar a ocupação pelo menos muito difícil e reduzir as flutuações. E isso pode ser feito inclusive com toda a pertinência requerida pelo complexo socioeconômico contemporâneo. Isto é, mesmo que não houvesse ameaças de dominação cultural, as nossas universidades não estão dando uma formação adequada para viver o século XXI.

\section{A prancha para evitar o desastre}

$\mathrm{Na}$ realidade, a solução não é difícil de ser implantada; é difícil de ser aceita. As universidades transnacionais vêm com seus currículos bem estruturados, conforme estabelecidos nas respectivas matrizes. Com as experiências de intercâmbio que foram adquirindo vão poder flexibilizar suas ofertas para encontrar apoio tanto na área acadêmica como na população, e principalmente na administração federal e nas estaduais. Mas, na onda de choque cultural por que passamos, não existem soluções únicas para estruturas curriculares, o que favorece a abertura de várias alternativas. Numa onda de choque surfa-se, não se nada. Surfar permite uma variedade ilimitada de estilos. Portanto vamos surfar.

O Brasil sofre de uma falha essencial na formação superior. Não há universidade no sentido essencial desse conceito. Não há formação integral em que os universitários, independentemente de suas preferências profissionais, sejam expostos às grandes questões filosóficas e sociológicas, à história da civilização, à organização socioeconômica do mundo em que vivemos entre outros temas que permitam tomar decisões como cidadãos conscientes e intelectualmente independentes sem ficarmos prisioneiros da exclusiva formação profissionalizante. Sem a educação integral, o responsável pela limpeza vai alvejar um rato no fundo do navio sem perceber que o tiro vai furar o casco e o navio afunda. Mas talvez pior ainda seja a mesma ignorância que afeta os passageiros que ainda fazem uma festa monumental, comemorando a morte do rato, sem se dar conta que estão afundando. Quando perceberem, não vai dar mais tempo para evitar o desastre. Os comandantes dos outros navios que estão na corrida comemoram com o herói matador de ratos. Essa é a tática genial da atualidade. Você não precisa atacar o adversário, ele mesmo se destrói. Isso ficou possível pelo extraordinário desenvolvimento tecnológico alcançado no nosso tempo, que leva na proa inteligência artificial e aprendizado de máquina (USA, 2016; Inglaterra, 2017; Villani, 2017) . 
É necessário e urgente reverter essa situação não só de ignorância, mas de formação incompleta, que pode ser pior que a ignorância. Os nossos cursos de graduação estão com uma grade curricular totalmente inadequada para as atuais demandas da sociedade moderna. É necessária uma reforma profunda (Taylor, 2005). Então devem-se concentrar esforços na implantação imediata de um novo currículo de graduação que, independentemente de invasão ou não, é urgente. A formação dos estudantes precisa atender os requisitos necessários à inclusão no mundo civilizado. Para resumir, entender Descartes: "je pense, donc je suis" e olhar para o céu em noite de lua nova. Isso é um currículo que explore temas necessários ao conhecimento de todo estudante universitário que pode ser resumido: "nós em nossa casa". O "nós" que está na raiz da afirmação cartesiana, na "nossa casa", isto é, o nosso universo, o nosso planeta, a nossa nação, a nossa cidade. Mas não basta, precisamos da linguagem, a matemática e a computação, a narrativa, as artes, e finalmente a transcendência, os mitos e as crenças. Disciplinas que cubram esses temas. Essa solução é a um tempo barreira a invasões a partir de novas propostas curriculares e preenchimento da necessidade imperiosa para a formação das novas gerações. Se conseguirmos essa proeza estaremos no caminho de uma legítima universidade. A solução em si não é difícil. O difícil é implantá-la. O difícil é converter um conjunto de escolas, institutos, departamentos reunidos em um campus em uma verdadeira universidade.

Mas só isso não basta, é preciso que se utilizem os instrumentos apropriados. Sem os processos de educação em massa pouco vão adiantar as alterações propostas. É muito interessante notar que a nova tecnologia de comunicação tida como uma das grandes novidades do nosso século é de fato o retorno à antiquíssima tradição oral. A diferença é que, hoje, nossa voz alcança o planeta inteiro. Se observarmos com cuidado, as novas técnicas de ensino em uso atualmente têm raízes profundas na tradição oral e de fato algumas são bastante eficazes. Os Massive Open Online Courses (MOOC) vão ser aperfeiçoados para aproveitar o nosso gosto intrínseco de falar mais do que escrever. $\mathrm{O}$ falar inclui experimentos, laboratórios virtuais e, sobretudo, memória. Apesar de se ter impressão contrária, aposto que a memória será novamente estimulada, pois é um atributo importante para a linguagem falada.

Precisamos, portanto, investir maciçamente em projetos de educação a distância. Os cursos devem ser elaborados com o máximo cuidado, com a máxima competência. Não basta que o expositor seja competente na matéria, é preciso que seja um excepcional comunicador; isto é, saber interagir com o interlocutor oculto. Os cursos preparados com o uso dessas novas tecnologias de comunicação estão apenas no início. Estão sendo desenvolvidas metodologias para torná-los mais eficazes e mais atrativos. Será preciso grande dedicação e competência para que eles ganhem valor pedagógico mais que valor comercial, que tem sido a motivação principal particularmente nas instituições privadas. 
Porém, sem dúvida esse é o novo instrumento que, junto com conteúdo original e adequado ao nosso tempo, vai definir quem continuará a participar do avanço e transmissão do conhecimento. $\mathrm{O}$ uso da rede de informação para educação a distância, certamente com os equipamentos que virão substituindo ou complementando os livros, constitui-se na prancha para navegar na grande onda de choque da nova organização do saber. Sem a prancha vamos ser engolfados. Esse ano o consórcio das academias americanas, através do conselho de ciências matemáticas, patrocinou um concurso em que os candidatos se apresentam com vídeos. Estamos já vivendo em um novo mundo (Marginson, 2011; Christensen; Eyring, 2011). Ou corremos rápido, ou seremos engolidos pela gigantesca onda que está já às nossas portas. Ou nos unimos em fortes consórcios de universidades públicas para fazer frente à invasão com chance de evitar o colapso cultural que começará a ser induzido pelas novas flutuações, ou seremos reduzidos à condição de um povo condenado à vida primitiva. Carnaval e futebol que hoje já nem têm o encanto do passado.

Não obstante o alerta de Henry Kissinger (2018) sobre o despreparo da nossa civilização para a era da inteligência artificial e aprendizado de máquina em excelente artigo, ela já despontou no horizonte do nosso futuro. Será determinante. Provavelmente provocará grandes perturbações; aliás, já estão acontecendo: a moderna versão da Torre de Babel. Mas após o grande choque, a nova conjuntura civilizatória se estabilizará em um novo ponto de equilíbrio. Onde estaremos nessa nova conjuntura depende ainda de nós, mas não por muito tempo.

\section{Os obstáculos}

Não obstante todas as mazelas que nos têm prejudicado, ainda há um fio de esperança segundo entendo e exponho acima. Mas também é certo que estamos cercados de grandes dificuldades e precisamos ser realistas. Não podemos nos ater a hipóteses otimistas que até podem se realizar, mas a variável principal agora é tempo. Não há mais tempo para esperar improváveis soluções. O que tem demonstrado a maioria dos discursos e ações do governo atual é, na melhor das hipóteses, a inversão de polaridade que toma o circunstancial pelo essencial. É catastrófico. Não há tempo para grandes revisões de atitude cultural que levam anos para ser implementadas. Precisamos identificar as falhas mais graves e agir para corrigi-las. É necessário andar na contramão e tentar salvar as sementes, ainda que sejam apenas para florescerem no futuro. Cabe à academia abrir essa passagem na contramão. Mas para isso são necessárias pelo menos duas atitudes: união e confiança nas suas próprias forças.

Só vejo uma alternativa para promover a união no curto prazo, que é recorrer ao poder de união que resta nas nossas associações, a começar pela Sociedade Brasileira para o Progresso da Ciência (SBPC), a Academia Brasileira de Ciências (ABC), a Academia Nacional de Medicina (ANM), a Academia Nacional de Engenharia (ANE), a Academia de Ciências do Estado de São Paulo 
(Aciesp), e todas as associações cientificas e tecnológicas. Se conseguirmos essa união, a implantação de um projeto consistente para a inundação do país com excelentes cursos construídos com os novos meios de comunicação será viável. Nós em nossa casa. A união das Fundações de Amparo à Pesquisa (FAP) também será importante para viabilizar a realização dos cursos.

O segundo propósito, a promoção da autoconfiança e independência intelectual, está intimamente associado com o emaranhado burocrático tradicional vigente e a visão polarizada pela lente construída pela nossa comunidade científica que só permite a passagem da luz em um sentido. Daqui vemos o que se passa fora e tentamos imitar. De fora não se vê o que se passa aqui e nos ignoram. Se me permitem, apresento um caso exemplar. Além disso, é recente e ilustrativo inclusive pelas atitudes que extrapolam os meios tradicionais de divulgação científica. Em novembro do ano passado, precisamente no dia 26, o New York Times publicou um artigo interessante assinado por Siobhan Roberts, com o título "This is the way the paper crumples in a ball of paper", e o subtítulo: "scientists discover a landscape of surprising mathematical order". O artigo foi escrito a propósito de uma publicação feita na Communications Physics - Nature na edição de novembro de 2018 sob o título: "A state variable for crumpled this sheets", de autoria de O. Gottesman, J. Andrejevic, C. H. Rycroft e S. M. Rubinstein, cientistas de Harvard e Berkeley. Os autores mostram que o método desenvolvido permite a descrição de um sistema altamente desordenado por um único parâmetro de estado que é o comprimento total dos vincos que se formam quando se amassa a folha de papel no formato de uma bola. Um trabalho bastante interessante. Visível daqui para lá inclusive com direito à atenção do NY Times.

Em 2002, portanto há dezesseis anos, um de nós que trabalhávamos no LNCC submeteu um trabalho para publicação no periódico "Applied Mathematical Modelling" sob o título "Fractal Balls". Depois de uma longa discussão com os revisores o trabalho foi aceito em 2003. e publicado na edição de 2004. Nesse trabalho demonstra-se que bolas de papel amassadas do mesmo modo como fizeram os autores citados anteriormente podem ser caracterizadas de fato por um único parâmetro, mas a opção foi outra, a sua dimensão fractal. E fico imaginando o que aconteceria se um dos prestigiosos jornais brasileiros publicasse, naquela ocasião, o fato de que pesquisadores se ocupam em amassar bolinhas de papel. A lição que podemos tirar é que nós somos invisíveis para a comunidade externa principalmente porque nos escondemos. São vários os fatores que contribuem para isso, mas é impossível eliminá-los no curto espaço de tempo que temos disponível. Devemos começar com a reforma de um dos principais que é a burocracia instalada na área científica. A burocracia atual induz à busca de rotas para o sucesso nas promoções individuais e notas de cursos de pós-graduação. As consequências são gravíssimas, porque induzem a permanência nas esteiras do conhecimento sem estímulo para pesquisas disruptivas. Há uma 
inversão de valores. Os critérios de avaliação deveriam estimular o avanço do conhecimento cuja consequência é progresso na carreira e melhor classificação das unidades acadêmicas. Na realidade estabelecem-se critérios de desempenho que buscam ser preenchidos com pouca atenção se de fato promovem o avanço científico ou tecnológico. Além disso, a burocracia favorece mais a cooperação externa do que a cooperação interna que deveria ser o foco principal do apoio científico e tecnológico. A burocracia estimula mais o uso de muletas do que a independência intelectual. A academia precisa sacudir esses pesos para poder progredir. É indispensável, eu afirmo indispensável, uma pacífica desobediência a esses critérios e estabelecer outros que de fato possam elevar o nível da nossa contribuição ao alargamento dos horizontes do saber. Sem ousadia sucumbiremos à onda da revolução cultural. Precisamos agora de muita humildade, união, competência e dedicação sem limites para sobreviver como nação capaz definir seus próprios rumos na trilha do conhecimento. Se a da tecnologia já perdemos, que se possa pelo menos preservar o pensar autônomo.

\section{Destino: Alexandria}

Até aqui, a reflexão a que me propus quando iniciei este breve texto. Mas, estando eu nos primeiro dos últimos anos de minha vida, e tendo aprendido que a história é uma aliada extraordinária na tomada de decisões e permite distinguir fatos de opiniões, permita-me o leitor fazer mais alguns breves comentários sobre uma notável revolução cultural, talvez a mais determinante na história da civilização ocidental.

Na realidade não é a primeira vez que acontece uma revolução cultural. Talvez a mais extraordinária de que se tem notícia aconteceu há 2.300 anos. Desenrolou-se ao longo de quase 600 anos no Egito. Morto Alexandre, que tinha plantado a semente da cidade que haveria de se tornar o polo da revolução cultural, o seu extenso reino foi dividido em quatro partes, depois de ferozes disputas entre os seus mais próximos correligionários. O norte da África compreendendo o Egito ficou sob o domínio de Ptolomeu, que optou por uma via não convencional na época. Talvez por ter frequentado o palácio de Felipe II na sua infância como amigo de Alexandre e participado da sua educação, que tinha Aristóteles com preceptor, tenha aprendido a apreciar o valor do conhecimento. Agora tinha o controle sobre uma rica região do norte de África. Grande produtora de grãos, atividade favorecida pelas margens férteis do Nilo, a cidade fundada por Alexandre tornou-se um centro comercial de exportação para outras regiões através do porto local (Vrettos, 2010).

Proclamado como primeiro imperador, rei ou faraó, não importa muito, Ptolomeu I, Soter, optou pelo saber. Poderia ter expandido o comércio e fundado a bolsa de valores financeiros da época, tornado Alexandria um atrativo para comerciantes, banqueiros, investidores, ou poderia ter organizado campanhas de conquistas de outros territórios, mas preferiu o conhecimento. O ganho da produção agrícola era destinado à construção de uma formidável cidade da inte- 
ligência. Como é um invariante da nossa condição humana, consta que um dos mecenas da época, que destinava consideráveis doações ao Museu e à Biblioteca, um poderoso comerciante e exportador, foi condenado por corrupção. No entanto, o comércio de grãos não foi interrompido, substituíram-se os desonestos, e os lucros, advindos do comércio, Ptolomeu I os destinava para a construção do museu e ampliação da biblioteca. J. Crawford (2017), em um breve mas muito bom artigo, relata:

Um dos relatos mais antigos que sobreviveu para fazer menção específica à biblioteca de Alexandria data do meio do segundo ou do terceiro século AC (a datação real é assunto de muito debate), escrita por Aristeas, um erudito judeu que veio morar e trabalhar na cidade. Em uma carta a seu irmão Philócrates, ele parece detalhar tanto o progresso extraordinário feito por Demétrius depois de ser colocado no comando da instituição, quanto o vasto escopo da tarefa definida por Ptolomeu:

[Demetrius] recebeu grandes somas de dinheiro com o objetivo de coletar, se possível, todos os livros do mundo; e organizando compras e transcrições, ele levou o projeto do rei à perfeição até onde pôde. Quando the perguntaram, na minha presença, quantos milhares de livros já haviam sido coletados, ele respondeu: "mais de duzentos mil, meu rei; e em breve vou me esforçar ao máximo para completar o que falta e chegar ao total de meio milhão".

Aristeas também relata seu próprio envolvimento na biblioteca, junto com outros 71 eruditos judeus, em um dos projetos mais significativos da história antiga: traduzir para o grego os escritos que mais tarde formariam o Antigo Testamento cristão.

Então a justiça era feita considerando todo o projeto de nação da época. A hierarquia de bens destinados ao progresso da cidade era inviolável. O progresso do saber era prioritário, Demetrius continuou a receber vultosas somas para continuar a desenvolver a biblioteca. Havia um projeto de cidade-nação a ser cumprido e isso era prioritário. Em outras palavras, a justiça podia ser cega, mas os outros sentidos eram apuradíssimos, sobretudo arguta, conhecia muito bem a hierarquia de valores que sustenta uma sociedade.

O projeto de Ptolomeu certamente não foi conduzido por seus antigos companheiros de batalha. Ptolomeu teve a felicidade de conviver com Aristóteles na sua juventude. Sabia que uma sociedade é tanto mais civilizada quanto mais fácil for o acesso ao conhecimento. Portanto deixou o projeto nas mãos dos sábios e de pessoas que valorizavam o saber. Alexandria com seu Museu e sua Biblioteca foi um polo de atração de filósofos, astrônomos, matemáticos, médicos, poetas, engenheiros, geógrafos, historiadores e tantos outros dedicados ao conhecimento científico. Destaco um feito extraordinário da época atribuído a Erastóstenes. Em primeiro lugar, sabendo que a terra é esférica, descobriu um método engenhoso de medir o raio dessa esfera terrestre. Há mais de 2.000 anos 
conseguiu determinar o seu valor com erro menor que 10\%. Uma curiosidade sobre esse cientista, ele era conhecido como "o beta", porque sem ser considerado o melhor em nenhum tema era o segundo em todos eles.

A determinação de Ptolomeu I impôs uma revolução cultural que deslocou o centro do mundo do saber de Atenas para Alexandria. Mas a insensatez humana não tem limites, nem no tempo, nem no espaço. O imperador general romano Caracala no século II de nossa era encarregou-se de destruir com grande atrocidade o que ainda sobrara de Alexandria depois de muitas guerras e ocupações bárbaras.

Pois bem, tudo isso para dizer que estamos vivendo uma era semelhante, embora com outros instrumentos de interação e comunicação. O Museu e a Biblioteca são outros hoje. Não estão em lugar nenhum e estão em todo lugar. No entanto, nós, seres humanos, somos os mesmos com a mesma coragem, sonhos e ideais e também com os mesmos medos, imediatismos e ambições. Continuam a existir Ptolomeus e Caracalas que se sucedem no governo das nações. O progresso tecnológico e a ambição humana colocam agora esse novo desafio, a reorganização do saber e mais da educação em novos centros com a diferença de que o poder de inibição é muito maior. A Paideia não tem mais âncora na civilização helênica, a nova âncora está sendo fixada nas bolsas de valores. É extraordinária a coincidência da fundação do cristianismo, que na realidade é uma seita judaica, com a ascensão do saber científico e filosófico em Alexandria. Permitiu a fé balizada pela razão proporcionando instrumentos para evitar o fanatismo religioso. A nova revolução cultural em marcha está invertendo o processo quer balizar a razão com conviç̧ões de fé. Vai favorecer o fanatismo. Portanto estamos com a polaridade invertida entre outros perigos de dominação. Não podemos deixar que isso aconteça pelo menos sem luta. Temos que recuperar os legítimos ideais da revolução cultural. Convido a todos os colegas a uma união sem precedentes, abandonando as pequenas diferenças que nada contam diante da tragédia anunciada. Uma união para manter invioláveis os princípios construídos ao longo de mais de 2.000 anos, liberdade para pensar, para expor as ideias, para ousar com coragem e humildade e para construir o nosso próprio destino sem necessidade de muletas.

Está para partir o último trem para Alexandria.

\section{Referências}

ALEMANHA, The Hamburg Declaration: Organizing Higher Education for the $21^{\text {st }}$ Century. Hamburg Transnational Universities Leaders Council, 2017.

ALPER, J. (Rapporteur) A Vision for The Future of Center-Based Multidisciplinary Engineering Research. In: PROCEEDINGS OF THE SYMPOSION, NAP, National Academy of Sciences, 2016.

ALTBACH, P. G.; REISBERG L. Responding to Massification-, $H$ de Witt, Report to 
the Hamburg Transnational University Leaders, commissioned by the Körber Foundation, 2017.

CHRISTENSEN, C. M.; EYRING, H. J. The Innovative University: Changing the DNA of Higher Education from the Inside Out, Jossey-Bass, A Wiley Imprint, www. josseybass.com, 2011.

CRAWFORD, J. The life and death of the Library of Alexandria. One of the great centers of human knowledge, ever. Literary Hub, March 13, 2017.

FACULDADE DE FILOSOFIA DA USP: lições inesquecíveis. Estudos Avançados, São Paulo, v.7, n.18, p.189-207, ago. 1993 . Disponível em <http://www.scielo.br/ scielo.php?script=sci_arttext\&pid=S0103-40141993000200008\&lng=pt\&nrm=iso $>$. Acesso em: 10 fev. 2019. http://dx.doi.org/10.1590/S0103-40141993000200008.

FAVERO, M. L. O titulo de doutor honoris causa ao rei dos belgas e a criação da URJ. Rio de Janeiro: Proedes/FE/UFRJ, 2000.

GREGORY C. The Industrial Revolution. University of California, Davis, CA 95616, gclark@ucdavis.edu, 2008.

INGLATERRA, The Royal Society. Machine learning: the power and promise of computers that learn by example, royalsociety.org/machine-learning, 2017.

JAMES, H. Charles W. Eliot, president of Harvard University, 1869-1909. AMS Press, 1930. v.1.

KISSINGER, H. How the Enlightenment Ends:Philosophically, intellectually-in every way-human society is unprepared for the rise of artificial intelligence. The Atlantic, 2018.

LANE, J.; KINSER, K. Is today's university the new multinational corporation? $T h e$ Conversation, Education, 2015.

MARGINSON, S. The modern university must reinvent itself to survive, The conversation. Australia, 2011.

MAZZUCATO, M. O Estado empreendedor: desmascarando o mito do setor público vs. setor privado. São Paulo: Portfolio-Penguin, 2014.

TAYLOR, M. End of the University as we know it. Newyork Tines, 2005.

USA. Executive Office of the President, Artificial Intelligence, Automation and the Economy. 2016.

VILLANI, C. L'intelligence artificielle est l'affaire de tout le monde. Le Monde, 2017.

VReTTOS, T. Alexandria. A Cidade do Pensamento Ocidental. 2.ed. S. 1.: Nova Alexandria, 2010.

RESUMO - A revolução industrial iniciada com o apoio do desenvolvimento científico do século XVIII introduziu modificações na estrutura social em todo o mundo. Artesãos foram dispensados, sendo a produção industrial transferida para os grandes complexos fabris. Países que não foram capazes de acompanhar a nova estrutura de produção, nem de privilegiar o conhecimento e a criatividade foram dominados e ficaram sujeitos a uma dependência socioeconômica que se prolonga até hoje. Nos nossos dias, está em marcha 
a "revolução cultural” sustentada pela tecnologia. Várias universidades vão ser descontinuadas, serão criados grandes centros transnacionais de produção científica e cultural, vários professores, os artesãos dos tempos modernos, serão dispensados e o aprendizado vai recorrer ao auxílio da rede de informação instalada no planeta. Estamos prestes a sermos engolidos pela nova revolução. Há saídas, mas precisamos de coragem, ousadia e muito trabalho em uma rede de cooperação nacional.

PALAVRAS-CHAVE: Revolução industrial, Revolução cultural, Nova universidade, Flutuações tecnológicas, Ensino a distância, Novos currículos, Cultura nacional, Alexandria.

ABSTRACT - The industrial revolution, which began supported by the scientific development of the 18th century, introduced changes in the social structure around the world. Craftsmen were dismissed and industrial production moved to large manufacturing complexes. Countries that were not able to adopt the new structure of production or to prioritize knowledge and creativity were dominated and subjected to a socio-economic dependency that continues to this day. Nowadays, we are plunged in a "cultural revolution" supported by extraordinary ongoing technological advances. Several universities will be discontinued; large transnational centers of scientific and cultural production will be set up; university professors, the craftsmen of our times, will be dismissed; and learning will have to resort to the information network installed on the planet. We are about to be swallowed up by the new revolution. There are ways out, but we need courage, daring and hard work in a network of national cooperation.

KEYWORDS: Industrial revolution, Cultural revolution, New university, Technological fluctuations, Online education, New curricula, National culture, Alexandria.

Luiz Bevilacqua é pesquisador visitante Instituto de Estudos Avançados da Universidade de São Paulo, professor emérito do Instituto Alberto Luiz Coimbra de PósGraduação e Pesquisa de Engenharia (COPPE) da Universidade Federal do Rio de Janeiro (UFRJ). @- beviluiz@gmail.com / https://orcid.org/0000-0002-7695-1385

Recebido em 8.2.2019 e aceito em 7.3.2019.

${ }^{\mathrm{I}}$ Instituto Alberto Coimbra, Universidade Federal do Rio de Janeiro, Rio de Janeiro. Brasil. 